\title{
Psychometric properties of a Persian version of respectful maternity care questionnaire
}

\author{
Mina Esmkhani ${ }^{1,2}$ (D), Masoumeh Namadian ${ }^{1,2^{*}}$ (D) Ali Nooroozy $^{3}$ (D) and Jeffrey E. Korte ${ }^{4}$ (D)
}

\begin{abstract}
Background: Providing high quality and respectful care during pregnancy and birth is one of the ways to reduce complications in women. Respectful care is a type of care that requires a valid instrument to measure. This study was conducted to determine the validity and reliability of the Persian version of the Respectful Maternity Care (RMC) questionnaire in 2018.
\end{abstract}

Methods: This study was performed with 150 women (in the first $48 \mathrm{~h}$ after birth), who were admitted in the postpartum wards of public hospitals from 1st January until 6th April 2018 in Zanjan city in Iran. Participants were selected randomly using the Poisson distribution (Time) sampling method. After receiving permission from the questionnaire's author, the internal consistency of the tool was measured by Cronbach's alpha coefficient after the Forward translation of the Persian version of the tool under expert supervision. The reliability of the modified questionnaire was assessed using a test-retest method in 10 eligible postpartum women, who completed the same questionnaire again after $72 \mathrm{~h}$. The validity of the tool was confirmed by exploratory and confirmatory factor analysis using LISREL and SPSS software.

Results: The original RMC tool achieved an overall high internal reliability $(a=0.839)$. Confirmatory factor analysis of original RMC scores demonstrated poor fit indices. In LISREL proposed paths for the model, one item was excluded and a re-exploratory factor analysis was performed with the remaining 14 items. Four new subscales were defined for the revised tool including Abusive Care, Effective Care, Friendly Care, and Respectful Communication, which explained $60 \%$ of the variance.

Conclusions: The revised tool included four subscales of Abusive Care, Effective Care, Friendly Care, and Respectful Communication in 14 items which explained $60 \%$ of the variance. Given the importance of providing high quality maternity care, and the variety of cultures and birth services across different countries, further research is needed on this RMC tool to evaluate its use in other countries and regions.

Keywords: Respectful maternity care, Psychometric, Validity, Reliability, Birth

\footnotetext{
* Correspondence: m.namadian@zums.ac.ir

${ }^{1}$ Social Determinants of Health Research Center, Zanjan University of Medical Sciences, Zanjan, Iran

${ }^{2}$ Nursing \& Midwifery Faculty, Zanjan University of Medical Sciences, Zanjan, Iran

Full list of author information is available at the end of the article
}

(c) The Author(s). 2021 Open Access This article is licensed under a Creative Commons Attribution 4.0 International License, which permits use, sharing, adaptation, distribution and reproduction in any medium or format, as long as you give appropriate credit to the original author(s) and the source, provide a link to the Creative Commons licence, and indicate if changes were made. The images or other third party material in this article are included in the article's Creative Commons licence, unless indicated otherwise in a credit line to the material. If material is not included in the article's Creative Commons licence and your intended use is not permitted by statutory regulation or exceeds the permitted use, you will need to obtain permission directly from the copyright holder. To view a copy of this licence, visit http://creativecommons.org/licenses/by/4.0/ The Creative Commons Public Domain Dedication waiver (http://creativecommons.org/publicdomain/zero/1.0/) applies to the data made available in this article, unless otherwise stated in a credit line to the data. 


\section{Background}

Pregnancy and childbirth can be considered an important time for women and their family. Despite the importance of this period, increasing maternal mortality rates and adverse consequences of pregnancy are general public health concerns. Reducing the complications of pregnancy in women and infants is one of the goals in the Third Millennium Development in which promoting prenatal care, birth and respectful care is one way to achieve this important goal [1, 2]. Providing a highquality and respectful care during pregnancy is one of the ways to reduce the complications of pregnancy in women and newborns, as disrespectful behavior by health care providers constitutes one of the barriers to attending health care facilities and receiving professional care [2]. Respectful maternity care throughout labour and birth has been recommended in the WHO guideline for having a positive childbirth experience [3]. The absence of respectful maternity care is being increasingly recognized as a deterrent to utilization and quality of maternity care [4]. In the last two decades, women have been encouraged to give birth in health care facilities to ensure access to skilled health care professionals. However, access to quality services is not guaranteed for many women; particularly for poor women. Disrespectful and undignified care is prevalent in many countries globally, and this not only disrespects their human rights but is also a significant barrier to accessing intrapartum care services [4]. In addition, health care systems in many parts of the world, which permit the health care provider to control the birthing process, may expose obviously healthy pregnant women to unnecessary medical interventions that interfere with the physiological process of childbirth [3]. The evidence suggests that women may decline to look for care when they have previously experienced disrespectful care and mistreatment, and may also discourage others from seeking care $[5,6]$.

Respectful Maternity care is a kind of client-centered care, based on respect for women's independence, expectations, authority, values, culture, and dignity. According to WHO recommendations, "Respectful maternity care refers to care organized for and provided to all women in a manner that maintains their dignity, privacy and confidentiality, ensures freedom from harm and mistreatment, and enables informed choice and continuous support during labour and childbirth" [3] This type of care is unique to each individual and his or her family, as each individual has a different family, cultural, social, and ideological background. Therefore, attention to individual differences is crucial in this type of care. According to the Human Rights Declaration, respectful care is an inalienable right of every woman [1, 2, 7-10]. The purpose of implementing respectful care is to: raise awareness and demand respectful care for clients, launch a national commitment to institutionalize maternal care as a standard of care and to mobilize communities and service providers to provide respectful care as a natural right of clients [10]. Respectful care measures are also taken to eliminate disrespect of, and abuse of clients. Several forms of abuse have been previously reported for women in hospital labour wards, including physical abuse (e.g. slapping), lack of privacy during examinations, disclosure of patients' secrets, disrespectful care, discrimination in providing services and utilization of hospital facilities, unnecessary episiotomies without the mothers' permission, and throwing infants on mother's abdomen [10]. Sheferaw et al. conducted a seven-week study to determine the validity and reliability of the Respectful Care Questionnaire in postpartum women. The Cronbach alpha reliability coefficient of the tool (questionnaire) was reported as $84 \%$ [2]. Despite the importance of this issue among vulnerable groups of society and the need for this type of care in the health system, there are very few tools for evaluating and implementing respectful care in Iran, such as the study carried out by Taavoni et al. [11]. In the study by Taavoni et al., one of the original versions of the 59-item Respectful Care Questionnaire was used among women who referred to the post-partum ward of a hospital in Tehran. The present study aimed to determine the psychometric properties and localization of the RMC Respectful Care questionnaire in Iran.

\section{Methods}

\section{Study aim and design}

This cross-sectional analytical study (Psychometric Analysis) was conducted to determine the psychometric properties of the Persian version of the RMC Respectful Care questionnaire which was developed by Sheferaw et al. [2].

\section{Ethics approval}

This research project received ethical approval (ZUMS.REC.1396.83) from the Vice Chancellor for Research of the Zanjan University of Medical Sciences. At the beginning of the study the purpose of the study was explained in detail for all participants, and the written informed consent of each participant was obtained.

\section{Study population and sampling}

This cross-sectional analytical study (Psychometric Analysis) was performed with 150 women who were selected using the Poisson distribution random sampling method (Time). Eligible subjects were therefore women at any age, with adequate psychiatric health, who were admitted to the postpartum wards of the public Mousavi Hospital from 1st January until 6th April, 2018 in Zanjan city, in Iran. All eligible women who consented to 
Table 1 Socio-demographic characteristics of participants

\begin{tabular}{|c|c|c|}
\hline Variable (N) & Groups & Frequency (\%) \\
\hline Educational level & Illiterate & $41(27.3)$ \\
\hline \multirow[t]{3}{*}{$(N=150)$} & No formal qualification & $64(42.7)$ \\
\hline & An standard high school qualification & $39(19.3)$ \\
\hline & An university degree & $16(10.7)$ \\
\hline Employment & Housewife & $136(91.9)$ \\
\hline$(N=148)$ & Employed & $12(8.1)$ \\
\hline Income sufficiency & Sufficient & $7(4.7)$ \\
\hline \multirow[t]{2}{*}{$(N=148)$} & Fairly sufficient & $26(17.6)$ \\
\hline & Insufficient & $115(77.7)$ \\
\hline Husband's employment & Public Job & $23(15.3)$ \\
\hline \multirow[t]{4}{*}{$(N=150)$} & Self-employed & $59(39.3)$ \\
\hline & Worker/ labor & $28(18.7)$ \\
\hline & Farmer & $37(24.7)$ \\
\hline & Unemployed & $3(2)$ \\
\hline Husbands' Educational level & Illiterate & $48(32)$ \\
\hline \multirow[t]{3}{*}{$(N=150)$} & No formal qualification & $65(43.3)$ \\
\hline & An standard high school qualification & $19(12.7)$ \\
\hline & An university degree & $18(12)$ \\
\hline
\end{tabular}

participate in the study completed the questionnaire in the first $48 \mathrm{~h}$ after birth.

\section{Questionnaire/tool and translating procedures}

In the present study, the original version of the Respectful Maternal Care (RMC) Questionnaire from Sheferaw et al. [2] was used after obtaining permission from the first author to translate and validate the RMC developed questionnaire in Iran. The RMC questionnaire was developed based on a review of the literature review, in-depth interviews with women who experienced labour and childbirth, followed by an expert review, measurement of face validity and content validity of the tool. A draft RMC scale with 37 items and two additional measures of global satisfaction, was administered to 509 postnatal care clients visiting facilities immediately after childbirth to 7 weeks postpartum in Ethiopia. The validity (consisting of criterion-related validity, content-related validity, and construct validity) and reliability $(\alpha=0.845)$ of the RMC scale was confirmed to assess the women's perception of respectful maternity care [2].

The RMC Questionnaire is a 15-item questionnaire, which is classified into four subscales on the basis of a 5-point Likert scale including; strongly agree (5), agree (4), don't know (3), disagree (2), and strongly disagree (1). The questionnaire included 4 dimensions of friendly care (first 7 questions), non-discriminatory care (questions 8, 9, 10), free care (questions 11, 12, 13) and timely care (questions 14, 15). Initially, the original questionnaire was translated to Persian from English (Forward translation-FWT). The translated questionnaire was then reviewed by five experts in reproductive health, health education, and epidemiology. The content validity of the translated questionnaire was determined through a review of the questionnaire by 10 experts (Reproductive Health, Health Education, and Epidemiology). The reliability (using a test-retest method) and internal consistency of the modified questionnaire was assessed in 10 eligible postpartum women, who completed the same questionnaire again after $72 \mathrm{~h}$. The modified questionnaire was completed by 150 eligible women (ten participants per item). The confirmatory and exploratory factor analyses were used to assess the construct validity.

\section{Statistical analysis}

Descriptive data analyses were performed using SPSS V.16 software to determine measures of central tendency (mean, median, and mode). To evaluate the normality of the data, the Kolmogorov-Smirnov test was used. Cronbach's alpha co-efficient and Pearson's Co-efficient of Correlation were used to measure internal consistency, and reliability (correlation) of modified questionnaire's items, respectively. The confirmatory and exploratory factor analyses were used to assess the construct validity. Psychometric analysis of the tool was performed using confirmatory factor analysis and LISREL Software. 
Table 2 Internal reliability for the Respectful Care Questionnaire and its subscales ( $N=150)$

\begin{tabular}{|c|c|c|c|c|}
\hline & $\begin{array}{l}\text { Item-total } \\
\text { correlation (r) }\end{array}$ & $\begin{array}{l}\text { Cronbach's Alpha } \\
\text { if Item Deleted }\end{array}$ & $\begin{array}{l}\text { Cronbach's Alpha } \\
\text { for subscales }\end{array}$ & $\begin{array}{l}\text { Total Cronbach } \\
\text { alpha }\end{array}$ \\
\hline \multicolumn{4}{|l|}{ Friendly care } & \multirow{8}{*}{$\begin{array}{l}0.839 \\
N=150\end{array}$} \\
\hline Q.1 I felt that health workers cared for me with a kind approach & 0.709 & 0.764 & \multirow[t]{7}{*}{0.813} & \\
\hline Q.2 The health workers treated me in a friendly manner & 0.644 & 0.777 & & \\
\hline Q.3 The health workers talked positively about pain and relief & 0.614 & 0.787 & & \\
\hline Q.4 The health worker showed his/her concern and empathy & 0.784 & 0.747 & & \\
\hline Q.5 All health workers treated me with respect as an individual & 0.552 & 0.795 & & \\
\hline $\begin{array}{l}\text { Q.6 The health workers spoke to me in a language that I could } \\
\text { understand }\end{array}$ & 0.343 & 0.825 & & \\
\hline Q.7 The health provider called me by my name & 0.276 & 0.830 & & \\
\hline \multicolumn{5}{|l|}{ Abuse- discrimination- Free Care } \\
\hline Q.8 The health worker responded to my needs whether or not I asked & 0.264 & 0.598 & \multirow[t]{3}{*}{0.469} & \\
\hline Q.9 The health provider slapped me during delivery for different reasons & 0.458 & 0.332 & & \\
\hline $\begin{array}{l}\text { Q.10 The health workers shouted at me because I haven't done what I } \\
\text { was told }\end{array}$ & 0.347 & 0.283 & & \\
\hline \multicolumn{5}{|l|}{ Free Care } \\
\hline Q.11 I was kept waiting for a long time before receiving service. & 0.646 & -0.010 & \multirow[t]{3}{*}{0.580} & \\
\hline Q.12 I was allowed to practice cultural rituals in the facility. & -0.063 & 0.795 & & \\
\hline $\begin{array}{l}\text { Q.13 Service provision was delayed due to the health facilities' internal } \\
\text { problem. }\end{array}$ & 0.675 & -0.059 & & \\
\hline \multicolumn{5}{|l|}{ Timely Care } \\
\hline $\begin{array}{l}\text { Q.14 Some of the health workers did not treat me well because of } \\
\text { some personal attribute. }\end{array}$ & 0.452 & - & \multirow[t]{2}{*}{0.516} & \\
\hline $\begin{array}{l}\text { Q.15 Some health workers insulted me and my companions due to } \\
\text { my personal attributed. }\end{array}$ & 0.452 & - & & \\
\hline
\end{tabular}

\section{Results}

The results of the data analysis with 150 women revealed that the mean age of participants was $28.9 \pm 6.2$. The women's age ranged between 15 and 43 , and $86 \%$ of them were less than 35 years old. Many of the women $(42.7 \%)$ and their spouses $(43.3 \%)$ had not completed high school, and 27.3 and $32 \%$ of women and their spouses were illiterate, respectively. Most of the women (91.9\%) were housewives, and their husbands were selfemployed (39.3\%). The majority of women (77.7\%) reported insufficient income for living cost (Table 1). In

Table 3 The Fitting index of Original RMC Tool

\begin{tabular}{ll}
\hline Chi-square & $674 / 51$ \\
$P$ value & $0 / 0000$ \\
df & 84 \\
RMSEA & 0.123 \\
SRMR & 0.14 \\
GFI & 0.84 \\
AGFI & 0.77 \\
\hline
\end{tabular}

terms of the mode of birth, $63 \%$ of women delivered by Cesarean Section (CS) and 37\% had Normal Vaginal Birth (NVB).

\section{Internal reliability and internal consistency}

The analysis of internal reliability of the original tool and related dimensions showed that the original RMC tool achieved an overall high internal consistency and reliability $(\alpha=0.839)$. (Table 2$)$. With the exception of the subscale of friendly care, other subscales of the instrument did not have a good internal consistency score in the target population (Table 2).

\section{Table $4 \mathrm{KMO}$ and Bartlett's Test}

\begin{tabular}{ll}
\hline Kaiser- Mayer- Olkin Measure of sampling Adequacy & 0.734 \\
Barlte's Test Sphericity Approx. Chi - Square & 1262.405 \\
Df & 91 \\
Sig & 0.000 \\
\hline
\end{tabular}


Table 5 Explanatory factor analysis for original version of RMC Tool

\begin{tabular}{|c|c|c|c|c|c|c|}
\hline \multirow[t]{2}{*}{ Factor } & \multicolumn{3}{|c|}{ Initial Eigen values } & \multicolumn{3}{|c|}{ Extraction sums of squared loading } \\
\hline & Total & $\%$ of variance & Cumulative $\%$ & Total & $\%$ of variance & Cumulative \% \\
\hline RMC 1 & 5.144 & 34.293 & 34.293 & 3.375 & 22.499 & 22.499 \\
\hline RMC2 & 2.232 & 14.878 & 49.171 & 2.211 & 14.740 & 37.239 \\
\hline RMC3 & 1.466 & 9.774 & 58.944 & 1.983 & 13.221 & 50.461 \\
\hline RMC4 & 1.244 & 8.295 & 67.240 & 1.297 & 8.644 & 59.105 \\
\hline RMC5 & 1.082 & 7.215 & 74.455 & 0.711 & 4.740 & 63.844 \\
\hline RMC6 & 0.801 & 5.343 & 79.797 & & & \\
\hline RMC7 & 0.771 & 5.138 & 84.935 & & & \\
\hline RMC8 & 0.525 & 3.502 & 88.437 & & & \\
\hline RMC9 & 0.434 & 2.895 & 91.332 & & & \\
\hline RMC10 & 0.388 & 2.588 & 93.920 & & & \\
\hline RMC11 & 0.286 & 1.905 & 95.826 & & & \\
\hline $\mathrm{RMC12}$ & 0.254 & 1.695 & 97.521 & & & \\
\hline $\mathrm{RMC13}$ & 0.187 & 1.247 & 98.768 & & & \\
\hline RMC14 & 0.152 & 1.017 & 99.784 & & & \\
\hline RMC15 & 0.032 & 0.216 & 100.00 & & & \\
\hline
\end{tabular}

\section{Factor analysis of the tool}

Factor analysis was used to analyze the questionnaire. The fitness indices obtained Chi-Square $=647 / 51$, $\mathrm{df}=$ $84, p$ value $<0.0001$. The results showed that the instrument did not have appropriate fitness indices (Table 3). LIZREL's proposed paths for model correction also had little effect on the fitness indices. Therefore, the obtained data were evaluated by exploratory factor analysis. At first, the sample size and its functionality were evaluated using KMO tests, Bartlett's test of Sphericity (Table 4). The results (Table 4) showed that the KMO was 734, indicating the suitability of the sample size. The Bartlett test was significant $(p<0.0001)$. Next, Maximum Likelihood and Varimax Rotation were used for exploratory factor analysis (Table 5). The results clarified 5 factors with Eigen values above one, (Fig. 1) (Table 6) explaining $63.84 \%$ of the variance. Examination of the Rotated Factor Matrix table showed that the Factor 5 had a factor loading only with item 7 , and item 7 had no factor loading with any of the items. Since a single item could not form a scale item, it was excluded from the study and a re-exploratory factor analysis was performed with the remaining items $(N=14)$. In the 14-item instrument, 4 factors with the highest eigenvalues were extracted, explaining $60.16 \%$ of the variance. The Scree Plot (Fig. 2), Explanatory Factor Analysis, and Rotated Factor Matrix table of these factors are as follows (Tables 7 and 8). Obviously, items number 9, 10, 14, and 15 loaded heavily on the first factor, so the items were defined as Abusive
Care. Items $6,8,11$, and 13 Loaded heavily on the second factor Therefore, the above items were defined as the Effective Care dimension. Items number 3, 4, and 5 items loaded heavily on the third factor, so the above items were named as Friendly Care. Finally, items 12, 2, and 1 loaded heavily on the fourth factor, defined as the Respectful Communication dimension.

\section{Discussion}

Given the importance of respectful care in different communities, and the lack of studies in this field in Iran, the present study conducted to determine the validity and reliability of the Persian version of the Sheferaw's Respectful Maternity Care. The target population in the present study was postpartum women who were transferred to the postpartum ward. One of the reasons for choosing the Sheferaw's tool (15 items) was the low number of items used in this questionnaire, to minimize the study burden on our target population of postpartum mothers. Sheferaw conducted a study in Ethiopia on 509 postpartum women within 7 days after birth. Data were collected using a 37-item questionnaire, with an in-person interview. After analyzing the findings, the final questionnaire with 15 items was presented as a Likert scale. The reliability of this tool was assessed using Cronbach's alpha coefficient (0.85). The results of the psychometric evaluation of Sheferaw's tool in the present study revealed that its dimensions and related items could not be used in its original form in the study population in Iran. The use of factor analysis on the items reported that: items Number 9,10, 14, and 15 had 


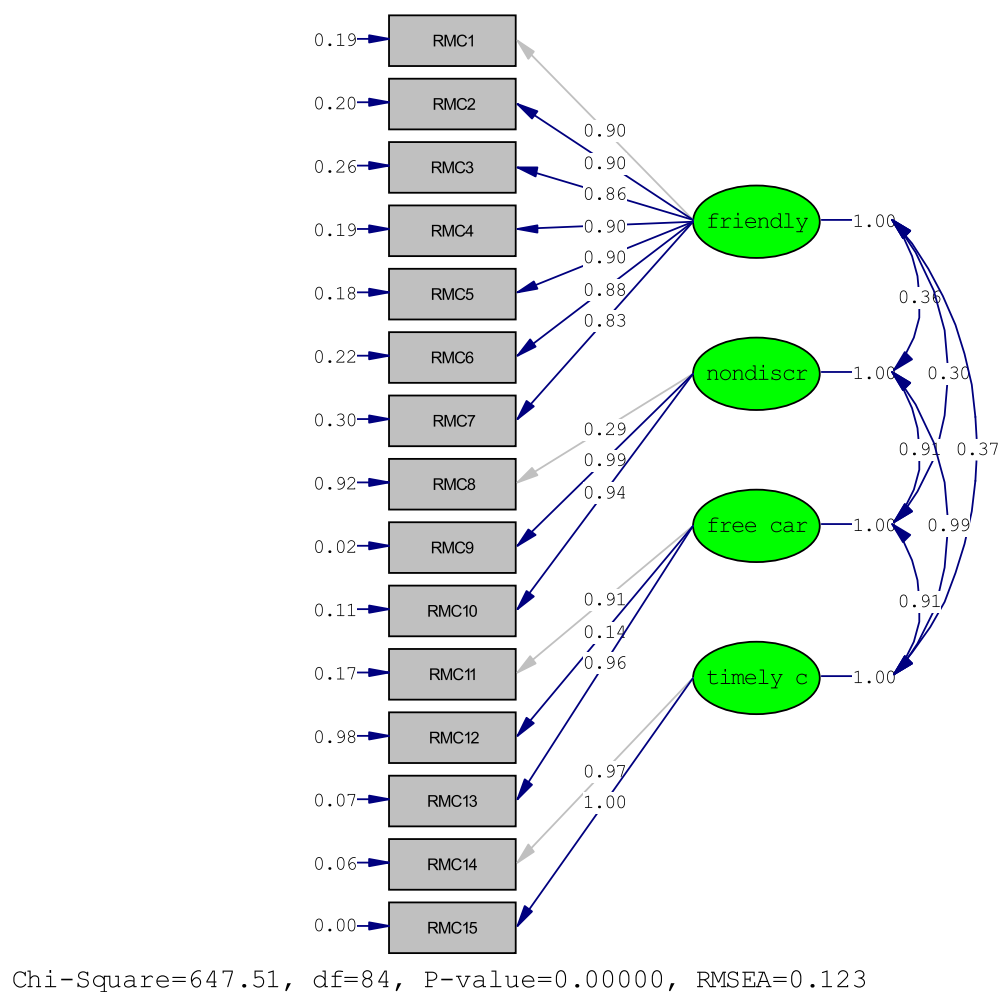

Fig. 1 Standardized solution for the proposed domains of the respectful Maternity Care QuestionnaireNote: All structural relationships are statistically significant $(p<0.01)$. For the sake of clarity correlations among exogenous variables and errors are not shown.

factor loading on number one, items number $6,8,11$, and 13 had factor loading on number two, items 3,4 , and 5 had factor loading on number 3 , and items number 12, 2 and 1 had factor loading on number 4 . For the present study, item No. 7 was removed as it had no effect on any of the other items, and the number of items was reduced to 14 . The dimensions of the items were named as 4 dimensions: Abusive Care, Effective Care, Friendly Care, and Respectful Communication. Cronbach's alpha for subscales was used to calculate the reliability of the four dimensions, with values of 0.757 , $0.717,0.765$, and 0.710 , respectively, indicating a good and acceptable Cronbach's alpha.

A review of the literature on psychometric studies of respectful care tools revealed that despite the importance of respectful care, especially in postpartum women, this area of research has received little attention from researchers in Iran. Therefore, the results of the few studies conducted in this field in Iran were compared. The only Iranian study available to the researchers in this study was the Taavoni et al. study in 2018, during which a new questionnaire of respectful care was designed, and the validity and reliability of the tool was determined. In their study, they used a questionnaire with 59 items in 7 dimensions, administered to women referred to health care centers for postpartum services. Their study showed that the QRMCQI ${ }^{1}$ instrument had an appropriate Cronbach's alpha $(0.93 \%)$ and the other items were within an acceptable range. Comparison of the present study with the Taavoni study clarified that the two studies were different in terms of the sample size under study and the instrument being measured. Given that the present study was designed with the primary aim of evaluating respectful care in the birth and postpartum ward, it seems that the tool used here, compared to the QRMCQI tool, as used immediately after birth, acted as revealing more accurate information compared to the results of Taavoni's study as women become more aware of the actions taken during and after the birth, which reduces the incidence of information bias and recall bias [11]. On the other hand, due to the greater need of women for respectful care during childbirth and postpartum care (due to unnecessary and repeated examinations, lack of privacy and hormonal changes after childbirth, psychological changes in maternal and newborns), it seems that more attention should be paid to the respectful care immediately after childbirth in Iran [12-15]. Based on these principles and considering the psychological conditions and length of hospitalization of mothers, the low number of items in the relevant

\footnotetext{
${ }^{1}$ The Quality of Respectful Maternity Care Questionnaire in Iran
} 
Table 6 Rotated factore matrixes

\begin{tabular}{|c|c|c|c|c|c|}
\hline & Facto & & & & \\
\hline & 1 & 2 & 3 & 4 & 5 \\
\hline RMC 9 & 0.971 & & & & \\
\hline RMC 15 & 0.961 & & & & \\
\hline RMC 10 & 0.472 & & & 0.353 & \\
\hline RMC 4 & & 0.783 & & & \\
\hline RMC 3 & & 0.699 & & & \\
\hline RMC 5 & & 0.531 & 0.398 & & \\
\hline RMC 14 & 0.398 & 0.441 & & & \\
\hline RMC 13 & & & 0.913 & & \\
\hline RMC 11 & & & 0.722 & & \\
\hline RMC 8 & & & 0.526 & & \\
\hline RMC 6 & & & 0.423 & & \\
\hline RMC 1 & & 0.550 & & 0.639 & \\
\hline RMC 2 & & 0.451 & & 0.626 & \\
\hline RMC 12 & & & & 0.541 & \\
\hline RMC 7 & & & & & 0.949 \\
\hline
\end{tabular}

Extraction Method: Maximum Likelihood

Rotation Method: Varimax with Kaiser Normalization

${ }^{\text {a }}$ Rotation Converged in 6 iteration

questionnaires, and its quickness, ease and low cost to implement, it seems that it is a useful tool. To our knowledge this is the first tool with all these criteria to be evaluated in Iran.

Another study by Rubashkin et al. in 2017 used an online survey on 501 mothers aged 18 to 45 years with an experience of natural childbirth or Cesarean section who had children aged less than 5 years. The research tool was a researcher-made questionnaire containing 111 questions in different dimensions. The results showed that the tool had a Context validity of
98\%. Compared to the tool used in the present study, it had the same differences of Taavoni's study regarding the number of items asked, the different community, the likelihood of bias, and the time taken to complete the questionnaire [16].

In the current study, confirmatory and then exploratory analyses were used to determine the construct validity of the instrument. The results of the current study are not in accordance with the results of Sheferaw's study regarding the items of each dimension as well as the internal reliability (in the original form of the tool). One of the main reasons for this difference could be the option to select "I don't know" at the center of the Likert scale (with score 3). In the Likert scale, the "do not know" option is expected to lead to a normal distribution and to avoid polarization of responses. There was no option for abstaining answers in the tool under study. According to AMEE GUIDE No. 87, the "No Comments" option should have been left out of the options [17]. Consideration of this in future studies can help to improve the tool. The present study is potentially the very first to validate this tool in Iran with a high sample size.

The limited generalizability of the results to the population under study is one of the limitations of this study. Our validation of this scale is only generalizable to women who attend public hospitals indicating specific socio-demographic characteristics, because the private hospitals did not agree to participate in the current study. The general health condition of participants at the time of filling the questionnaires was another limitation. Finally, another limitation of this study may have been social desirability bias stemming from women's reluctance to truthfully answer the questions, if they were concerned that their answers could affect the quality of their health care.

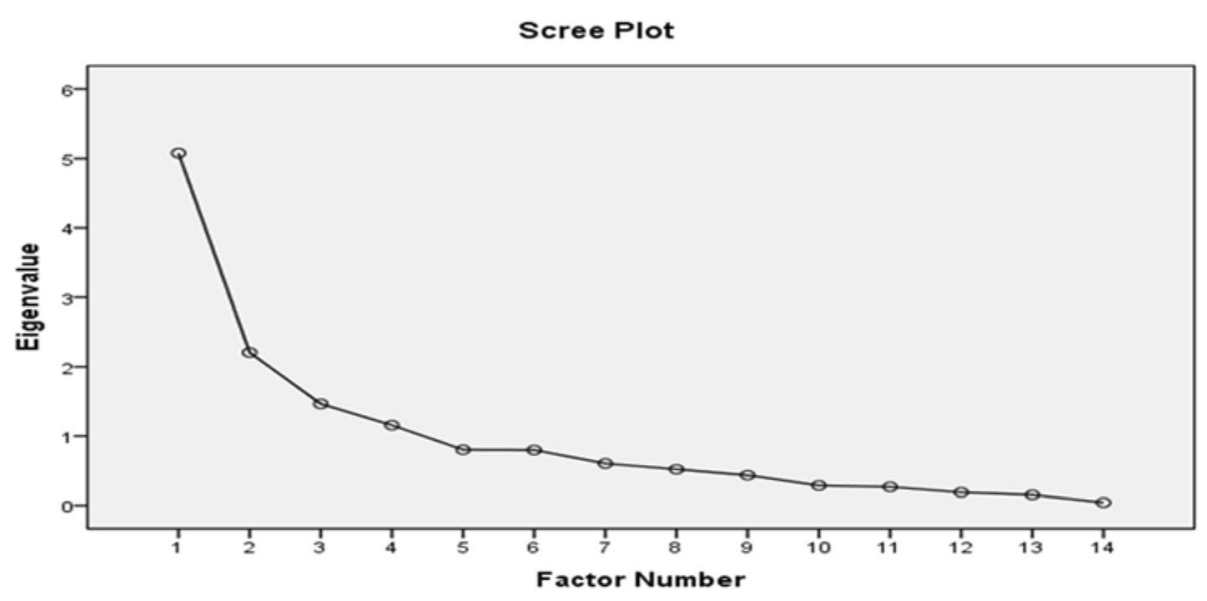

Fig. 2 The number of Eigen Values higher than one 
Table 7 Explanatory factor analysis for Revised version of RMC Tool (14 items)

\begin{tabular}{|c|c|c|c|c|c|c|}
\hline \multirow[t]{2}{*}{ Factor } & \multicolumn{3}{|c|}{ Initial Eigen values } & \multicolumn{3}{|c|}{ Extraction Sums of Squared Loading } \\
\hline & Total & $\%$ of Variance & Cumulative (\%) & Total & $\%$ of Variance & Cumulative (\%) \\
\hline RMC 1 & 5.080 & 36.285 & 36.285 & 3.661 & 26.150 & 26.150 \\
\hline RMC2 & 2.206 & 15.754 & 52.039 & 2.778 & 19.840 & 45.990 \\
\hline RMC3 & 1.465 & 10.461 & 62.500 & 1.250 & 8.930 & 54.920 \\
\hline RMC4 & 1.156 & 8.259 & 70.759 & .734 & 5.240 & 60.160 \\
\hline RMC5 & .802 & 5.727 & 76.486 & 3.661 & 26.150 & 26.150 \\
\hline RMC6 & .798 & 5.699 & 82.185 & 2.778 & 19.840 & 45.990 \\
\hline RMC7 & .603 & 4.309 & 86.494 & & & \\
\hline RMC8 & .520 & 3.716 & 90.210 & & & \\
\hline RMC9 & .434 & 3.102 & 93.312 & & & \\
\hline RMC10 & .286 & 2.046 & 95.358 & & & \\
\hline RMC11 & .267 & 1.906 & 97.264 & & & \\
\hline $\mathrm{RMC12}$ & .189 & 1.349 & 98.612 & & & \\
\hline $\mathrm{RMC13}$ & .153 & 1.092 & 99.704 & & & \\
\hline $\mathrm{RMC14}$ & .041 & .296 & 100.000 & & & \\
\hline
\end{tabular}

\section{Conclusion}

The revised RMC questionnaire included four subscales of Abusive Care, Effective Care, Friendly Care, and Respectful Communication in 14 items which explained a large proportion of the variance. The revised RMC questionnaire in Iran would be an appropriate tool for evaluating respectful care in women who have given birth, as it includes a low number of questions, examines four dimensions of respectful care, and has a high internal

Table 8 Rotated factore matrix for revised version of RMC tool

\begin{tabular}{|c|c|c|c|c|}
\hline & Factor & & & \\
\hline & 1 & 2 & 3 & 4 \\
\hline RMC 15 & 0.966 & & & \\
\hline RMC 9 & 0.961 & & & \\
\hline RMC 10 & 0.479 & & & 0.392 \\
\hline RMC 14 & 0.411 & & & \\
\hline RMC 13 & & 0.913 & & \\
\hline RMC 11 & & 0.725 & & \\
\hline RMC 8 & & 0.516 & & \\
\hline RMC 6 & & 0.426 & & \\
\hline RMC 4 & & & 0.846 & \\
\hline RMC 3 & & & 0.683 & \\
\hline RMC 5 & & 0.400 & 0.531 & \\
\hline RMC 1 & & & 0.508 & 0.652 \\
\hline RMC 2 & 0.356 & & 0.417 & 0.647 \\
\hline RMC 12 & & & & 0.537 \\
\hline
\end{tabular}

Extraction Method: Maximum Likelihood

Rotation Method: Varimax with Kaiser Normalization

${ }^{\text {a }}$ Rotation Converged in 5 iteration reliability in the Iranian population. This revised questionnaire therefore could be used as a valid tool in all health and medical centers to measure the level of respectful care, as one of the pillars of clients' rights, and consequently would result in improvement of the quality of care, the services provided and the satisfaction of clients. Due to the importance of respectful care in improving the health care system and outcomes, and the limited number of relevant studies in Iran, further research in different communities are recommended.

\section{Abbreviations}

RMC: Respectful Maternity Care; CS: Cesarean Section; NVB: Normal Vaginal Birth

\section{Acknowledgements}

The researchers gratefully acknowledge all women who participated in the study for their contribution to this study; without them there would be no data. The researchers would like to thank from Dr. Kamali K. and Dr.

Shakibazadeh E. for their valuable advice.

\section{Authors' contributions}

All authors participated in the research and preparation of the manuscript, and all have reviewed and approved the manuscript as submitted and take public responsibility for it. MN (Masoumeh Namadian) and ME (Mina Esmkhani) contributed to designing the proposal; ME undertook the data collection and data entry, MN, AN (Ali Nooroozy) and ME conducted the data analysis, MN and ME wrote the first draft of the manuscript; JEK contributed to the design of the proposal and the drafting of the manuscript; MN prepared the final draft of the manuscript.

\section{Funding}

This research project was approved by Social Determinants of Health research center, and funded by the Research Vice-Chancellor of Zanjan University of Medical Sciences (Grant Number: A-11-147-8). The funders had no role in the study design, data collection, analysis, and interpretation of data, or writing of the manuscript. Dr. Korte's time on this project was funded, in part, by the National Institutes of Health under Grant Number UL1 TR001450. 
The content is solely the responsibility of the authors and does not necessarily represent the official views of the National Institutes of Health.

\section{Availability of data and materials}

The data that support the findings of this study are available from Zanjan University of Medical Sciences but restrictions apply to the availability of these data, which were used under license for the current study, and so are not publicly available. Data are however available from the authors upon reasonable request and with permission of Zanjan University of Medical Sciences.

\section{Declarations}

\section{Ethics approval and consent to participate}

The present study has been performed in accordance to the ethical standards as laid down in the Declaration of Helsinki, and ethical approval was obtained from the Research Committee of Zanjan University of Medical Sciences (NO. IR. ZUMS.REC.1396.83). Written informed consent was received from each participant and the purpose of the study was explained to a participant before the data collection.

\section{Consent for publication}

Not applicable.

\section{Competing interests}

The authors declare that they have no competing interests.

\section{Author details}

'Social Determinants of Health Research Center, Zanjan University of Medical Sciences, Zanjan, Iran. ${ }^{2}$ Nursing \& Midwifery Faculty, Zanjan University of Medical Sciences , Zanjan, Iran. ${ }^{3}$ Education Development Center, Zanjan University of Medical Sciences, Zanjan, Iran. ${ }^{4}$ Department of Public Health Sciences, Medical University of South Carolina, Charleston, SC, USA.

\section{Received: 23 July 2020 Accepted: 3 March 2021}

Published online: 18 March 2021

\section{References}

1. Ponndara Ith DA, Homer CSE. Women's perspective of maternity care in Cambodia. Women Birth. 2013;26(1):71-5.

2. Sheferaw ED, Mengesha TZ, Wase SB. Development of a tool to measure women's perception of respectful maternity care in public health facilities. BMC Pregnancy Childbirth. 2016;16(67):2-8.

3. World Health Organization. WHO recommendations: intrapartum care for a positive childbirth experience. Geneva: World Health Organization; 2018. p. 3-8. Licence: CC BY-NC-SA 30 IGO p: . 2018

4. Vogel JP, Bohren MA, Tunçalp Ö, Oladapo OT, Gülmezoglu AM. Promoting respect and preventing mistreatment during childbirth. BJOG. 2016;123(5): 671-4.

5. Bohren MA, Hunter EC, Munthe-Kaas HM, Souza JP, Vogel JP, Gülmezoglu AM. Facilitators and barriers to facility-based delivery in low- and middleincome countries: a qualitative evidence synthesis. Reprod Health. 2014; 11(1):71.

6. Bohren MA, Vogel JP, Hunter EC, Lutsiv O, Makh SK, Souza JP, et al. The mistreatment of women during childbirth in health facilities globally: a mixed-methods systematic review. PLoS Med. 2015;12(6):e1001847 discussion e.

7. Kazemi Karyani A, Azami SR, Rezaei S, Shaahmadi Savojbolagh F, Ghazanfari S. Geographical distribution of gynecologists and midwives in Kermanshah province (2008-2013). J Kermanshah Univ Med Sci (BEHBOOD). 2015;19(5): 294-302.

8. Transforming Maternity Care Vision Team. 2020 vision for a high-quality, high-value maternity care system. Womens Health Issues. 2010;20(1):7-17.

9. Rosen HE, Lynam PF, Carr C, Reis V, Ricca J, Bazant ES, et al. Direct observation of respectful maternity care in five countries: a cross-sectional study of health facilities in east and southern Africa. BMC Pregnancy Childbirth. 2015;15(1):306.

10. Windau-Melmer T. A Guide for advocating for respectful maternity care Washington, DC: Futures Group, Health Policy Project; 2013. p. 1-19.

11. Taavoni S, Development GZ. Assessment of respectful maternity care questionnaire in Iran. Int J Community Based Nurs Midwifery. 2018;6(4):334.
12. Abedini S, Golmakani N, Behdani F, Esmaeili H, Safa O. Comparing marital satisfaction between women with and without. Hormozgan Med J. 2006; 10(3):251-6.

13. Alidosti M, Tahmasebi M, Raeisi M. Evaluating the women's satisfaction of Hajar hospital services after the delivery. J Clin Nurs Midwifery. 2013;2(1):1-8.

14. Martin A, Horowitz C, Balbierz A, Howell EA. Views of women and clinicians on postpartum preparation and recovery. Matern Child Health J. 2014;18(3): 707-13.

15. Mirmolaei T, Amel Valizadeh M, Mahmoodi M, Tavakkol Z. The effect of postpartum care at home on maternal received care and satisfaction. Evidence Based Care. 2011;1(1):35-50.

16. Rubashkin N, Szebik I, Baji P, Szántó Z, Susánszky E, Vedam S. Assessing quality of maternity care in Hungary: expert validation and testing of the mother-centered prenatal care (MCPC) survey instrument. Reprod Health. 2017;14(1):152.

17. Artino AR Jr, La Rochelle JS, Dezee KJ, Gehlbach H. Developing questionnaires for educational research: AMEE Guide no. 87. Med Teach. 2014;36(6):463-74. https://doi.org/10.3109/0142159X.2014.889814.

\section{Publisher's Note}

Springer Nature remains neutral with regard to jurisdictional claims in published maps and institutional affiliations.

\section{Ready to submit your research? Choose BMC and benefit from:}

- fast, convenient online submission

- thorough peer review by experienced researchers in your field

- rapid publication on acceptance

- support for research data, including large and complex data types

- gold Open Access which fosters wider collaboration and increased citations

- maximum visibility for your research: over $100 \mathrm{M}$ website views per year

At BMC, research is always in progress.

Learn more biomedcentral.com/submissions 